\title{
Study of Contaminants Index of Musi River Command Area
}

\author{
Mohammed Zakir Hussain ${ }^{1}$ and Ravi Kant Sharma ${ }^{2}$ \\ ${ }^{1}$ Research Scholar, Shri JJTU, Department of Environmental Sciences, Jhunjhunu, India \\ ${ }^{2}$ Associate Professor, Shri JJTU, Department of Environmental Sciences, Jhunjhunu, India
}

\section{ABSTRACT}

The cause of this study is to investigate the broad Contaminants Index (CCI) of the study area vicinity with a view to investigate the water pollution level of the four hundred-year-antique Musi River located in Hyderabad Telangana. The study is done in view of sustainable development. Water samples had been gathered from villages, which might be 15 $\mathrm{km}$ away from each other as a consequence, a complete of $60 \mathrm{~km}$ downstream villages belt were considered to examine the contaminants index. A composite sampling technique is used to collect samples from sampling locations following a standard way to obtain a representative samples. There were total 9 physiochemical properties hadbeen analyzed and the facts had been seen in comparison with (WHO) and BIS standards. The complete pollution index values for the four sampling sites are 2.0, 1.61, 1.4 and 1.thirteen, respectively, indicating that the pollution in the direction of the downstream is reducing but, those areas are considered as medium polluted due to the fact these values fall into category four consistent with the CPI score. At the start of the have a look at place, CPI suggests excessive eutrophication hazard. This look at can be an alternative for determining the level of pollution, indicating pollutants, and decision making of the use of water.

\section{KEY WORDS: CPI, MUSIRIVER, DOWNSTREAM, AND POLLUTION.}

\section{INTRODUCTION}

Water is a vital commodity, both to sustain life and for the global economy. However, the quality of global water has rapidly declined for decades due to the impact of both natural and anthropogenic factors (Vadde et al. 2018). Assessing water quality for different water use purposes, such as domestic use, irrigation, conservation and industrial usage, are an important strategy for food safety and human health. Water quality evaluation aims to identify the sources of water pollution and develop

\section{ARTICLE INFORMATION}

Received 21st Oct 2020 Accepted after revision 18th Dec 2020 Print ISSN: 0974-6455 Online ISSN: 2321-4007 CODEN: BBRCBA

Thomson Reuters ISI Web of Science Clarivate Analytics USA and Crossref Indexed Journal

\section{Clarivate
Analytics}

NAAS Journal Score 2020 (4.31)

A Society of Science and Nature Publication,

Bhopal India 2020. All rights reserved.

Online Contents Available at: http//www.bbrc.in/

Doi: http://dx.doi.org/10.21786/bbrc/13.15/33 a strategy for sustainable water source management, maintaining and promoting human health and other social and economic growth (Carroll et al. 2006). Surface water quality indexes have been developed and introduced worldwide by researchers with various applications of the Nation Sanitation Foundation Water Quality Index (NSFWQI) (Carroll et al. 2006), the Water Quality Index (WQI) (Gupta et al. 2003). The Comprehensive Pollution Index (CPI) (Matta et al. 2017).

\subsection{Study Area}

\section{MATERIAL AND METHODS}

Actual samples collected in the bottles and filled to the surface until overflow after sampling, nitric acid $(1.0 \mathrm{mg} / \mathrm{L})$ was added to all the samples as a preservative.The water sample were tested for their physical-chemical properties. All parameters had been dissected by standardized techniques, Ph, TDS,, Alkalinity, TotalHardness, Ca, 
Nitrate,BOD, COD and Ammoniacal Nin order to test the standard methodologies recommended by APHA was used.

Figure 1: Study area location

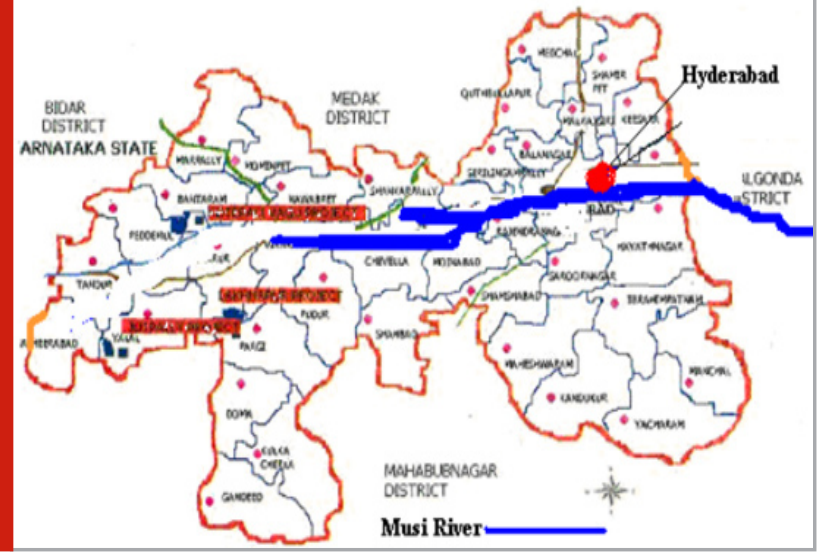

\section{RESULTS AND DISCUSSION}

The CPI is used to access the level of pollution in a specific river by using monitoring statistics (Liu \& Zhu 1999). The formula to calculate CPI is presented as follows: The interpretation of results are subjected to statistical analysis using comprehensive pollution index equationCPI $=1 / \mathrm{n}$ summation of Pli. Where CPI $=$ Comprehensive Polluted Index; $\mathrm{n}=$ number of monitoring parameters; $\mathrm{Pli}=$ the pollution index number i. Pli is calculated according to the following equation: Pli $=\mathrm{Ci} / \mathrm{Si}$ where $\mathrm{Ci}=$ measured concentration of parameter number in water; $\mathrm{Si}$ = permitted limitation of parameter number according to environmental standard.

CPI is classified into five categories: 1 . Category 1: CPI from 0 to 0.20 (clean); 2. Category 2: CPI from 0.21 to 0.40 (sub clean); 3. Category 3: CPI from 0.41 to 1.00 (slightly polluted); 4. Category 4: CPI from 1.01-2.00 (medium polluted); 5. Category 5: CPI more than 2.01 (heavily polluted).



Table 2. Comprehensive pollution analysis

\begin{tabular}{|l|c|c|c|c|}
\hline Parameters & PliPratapasingaram & PliEnkriyala & PliSurapally & Pli (Aroor) \\
\hline Ph & 1.3 & 1.2 & 1.1 & 1.0 \\
\hline TDS & 8.2 & 1.7 & 1.6 & 1.5 \\
\hline Alkalinity & 1.9 & 1.1 & 0.7 & 0.6 \\
\hline TH & 3.7 & 3.5 & 3.4 & 3.3 \\
\hline Ca & 2.5 & 2.5 & 2.4 & 2.3 \\
\hline Nitrate & 2.0 & 1.9 & 1.8 & 1.6 \\
\hline B.0.D & 1.4 & 1.2 & 0.8 & 0.2 \\
\hline COD & 1.1 & 1.0 & 0.8 & 0.3 \\
\hline Ammoniacal N & 1.3 & 1.1 & 0.9 & 0.0 \\
\hline Sum of Pli & 23.3 & 15.2 & 13.6 & 10.8 \\
\hline CPI & 2.59 & 1.69 & 1.51 & 1.20 \\
\hline
\end{tabular}

According to the CPI's classification, this river was under heavily pollutedcatgory this may be because of the dump of solid waste, untreated intrusion of industrial effluent and also untreated sewage water intrusion. The CPIs were different among the monitoring points upstream, midstream and downstream. Now the government has taken very good action to clean the river water but the best recommendation here is to prevent the intrusion of waste into it. 


\section{CONCLUSION}

Understanding the water quality is very important, it is concluded that CPI indicates a high eutrophication risk. This study may be an option for determining the current state of water quality, indicating pollution, and making water use decisions.

\section{REFERENCES}

Carroll S. P. Dawes L. Hargreaves M. Goonetilleke A. 2006 Water Quality Profile of an Urbanising Catchment -Ningi Creek Catchment. Technical Report. School of Urban Development, Queensland University of Technology, Caboolture Shire Council, QLD, Australia, pp. 1-93.

Gupta A. K. Gupta S. K. Rashim S. P. 2003 A comparison of water quality indices for coastal water. J. Environ. Sci. Health, Part A 38 (11), 2711-2725.Google Scholar Liu S. Zhu J. P. 1999 Comparison of several methods of environment quality evaluation using complex indices. Environ. Monit. 15, 33-37.Google Scholar

Matta G. Kumar A. Uniyal D. P. Singh P. Kumar A. Dhingra G. K. Ajendra K. Naik P. K. Shrivastva N. G. 2017 Temporal assessment using WQI of River Henwal, a Tributary of River Ganga in Himalayan Region. Int. J. Environ. Rehabil. Conserv. 8 (1), 187-204.Google Scholar

Vadde K. K. Jianjun W. Long C. Tianma Y. Alan J. Raju S. 2018 Assessment of water quality and identification of pollution rick locations in Tiaoxi river (Taihu watershed), China. Water 10, 183.Google Scholar 